\title{
Liquidity offer in order driven markets
}

\author{
Kaltoum Lajfari ${ }^{1}$ \\ ${ }_{1}^{1}$ (UFR Monnaie Finance Banque/Universite Mohamed VAgdal Rabat, Maroc)
}

\begin{abstract}
Being an essential quality of the financial markets, market liquidity represent a big concern for both, financial authorities and investors. Liquidity offer depends on several parameters including the mode of organization of exchanges. In order driven market, limit order plays a central role in liquidity offer. However, it represents many risks to the investor in contrast with a market order.

Keywords: market liquidity, liquidity offer, order driven market, limit order, limit order risks.
\end{abstract}

\section{Introduction}

In contrast to quote driven market, where the market maker is a liquidity provider, in order driven markets, orders are confronted on an order book, and liquidity offer is ensured mainly by limit orders.

According to their degree of patience, investors in an order driven market, have the option to either place buy and sell orders and to be liquidity providers, or to be executed immediately against offerings from other investors and being liquidity seekers. Thus, the supply and demand of liquidity differ by the choice of the types of order that is placed.

In order driven markets, there are several types of order models that differ in their degree of aggressiveness. If the liquidity offer in an order driven market is provided by limit orders, demand for liquidity is provided by market orders.

Unlike liquidity seekers, who are looking for the immediacy of the exchanges, multiple are the risks that liquidity providers face. In addition to the risk of non-execution, in an information asymmetry situation, the investor placing a limit order offers an option to the market for free (free trading option risk). Thus, liquidity offer remuneration represents a mean to cover the various risks incurred by the placement of limit orders.

\section{Limit Order And Liquidity Offer In Order Driven Markets}

In order driven markets, patient traders supply liquidity to urgent traders, by placing limit orders. The "patient" trader will not choose to place a limit order unless the expected gain from transacting with a liquidity trader exceeds the expected loss from transaction with an informed trader.

\subsection{Liquidity supply and demand in order driven markets}

The exchange organization impact directly the process of liquidity supply on the financial markets. On the market, some investors are liquidity providers (patient investors), while others are liquidity consumers (urgent investors).

In contrast to quote driven markets where the market maker plays the role of a liquidity provider, in an order driven market, no market intermediary is obliged to provide liquidity. Hence, liquidity supply in a quote driven market rely on the market maker, on order driven markets, orders are confronted on an order book, and the liquidity supply is ensured mainly by the limit orders book.

According to their attitude on immediacy, investors in an order driven market have the option to either place buy and sell orders and being liquidity suppliers, or to be executed immediately and being liquidity consumers. The type of the order placed (market order or limit order) reflects the traders' choice.

The liquidity consumer determines the amount to exchange after observing quotations of liquidity providers in a quote driven market Liquidity supplier, shall submit a limit order, that allows him/her to set the maximum (minimum) price at which he/she is ready to buy (sell) securities. In the case the investor is a liquidity consumer, he/she submits an order at any price.

On this type of market, the investor strategy includes the choice of the amount exchanged, the choice of the price at which he wishes to exchange and in the case of limit orders the choice of validity, period during which the offer is valid.

If the liquidity supplier runs several risks, liquidity consumers avoid these risks by submitting orders that the execution is immediate. In return, they pay the spread imposed by liquidity providers. In addition, there may be a risk of price, also called market impact, if the quantity demanded is greater than the quantity available. Liquidity supply in this structure is provided by the traders. They have the choice between being liquidity providers using limit orders, or liquidity consumers by placing market orders. 
There are two types of investors in an order driven market. We distinguish the urgent traders who place market orders. They are liquidity consumers. Meanwhile, patient traders, place limit orders, and represent liquidity providers.

\subsubsection{Degree of aggressiveness in liquidity demand:}

The most aggressive orders are buy orders (or sell orders) with a higher price (lower) than the best selling price ( buying price) in the order book and with a greater size than the available size at the same price.

Moderately aggressive orders are buy orders (sell orders) that the price is equal to the best-selling price (buying price), but that the size exceeds the depth available at this price.

Non-aggressive orders are orders that price is equal to that of the best proposed limit and that the size is less than or equal to the depth available at this price.

\subsubsection{Degree of aggressiveness in liquidity supply}

The most aggressive orders are buy orders (sell orders) that the price is lower (greater) than the best selling price (buying price) currently displayed.

Moderately aggressive orders are buy orders (sell orders) that the price is just equal to the best buying price selling price) already included in the order book.

Non-aggressive orders represent the most passive orders. The buy orders price (sell orders price) is lower (higher) than the best buying price (selling price) existing in the order book at the same time.

The functioning of an order driven market is based on the liquidity supply by patient investors, who are not looking for immediacy in the exchange, in contrast to liquidity consumers. However, liquidity providers face a trade-off between the benefit of placing a limit order and the risks this type of orders involves.

\subsection{Limit orders features, probability of execution, and competition between liquidity providers}

Immediate liquidity offer in an order driven market comes from limit orders. All limit orders which are waiting during the negotiation phase continue to offer immediate liquidity until the market closes.

Market Orders that are placed during the rest of the trading day will absorb the offer of immediate liquidity. Pending their execution, limit orders face several risks, since the execution will take place or not.

A limit order can remain indefinitely on hold if better orders are available on the side of the liquidity supply. On the other hand, empirical works have shown that new limit orders begin to focus within the spread, which impacts negatively the probability of execution ${ }^{1}$.

The order book includes all buy and sell orders issued on an order driven market, classifies and matches them. Orders (bids and asks) are placed on the order book and faced with existing orders. If orders don't meet a counterparty, they are stored in the order book.

The classification of orders is done according to the priority rule: the time priority and the price one. The execution speed depends on the proposed price: in the case of a buy order, the higher price and in the case of sell order the lowest price. For the time priority, the order that arrived first is the first executed.

The limit order is characterized by a certain price and a certain quantity. In fact, it represents an order with restrictions on the maximum price to be paid and the minimum price to be received combined with the corresponding quantities.

Investors who place limit orders are supposed to have no information, whereas informed investors, to benefit from their information, the latters place orders with immediate execution.

A buy limit order (of sell limit order) is characterized by a quantity and the (minimum) maximum price at which the limit order underwriter is ready to buy (sell) the security. Accordance with priority rules (price and time). The orders, that are not executed immediately, accumulate in the order book.

So as a first step, orders are sorted by price, giving priority to orders at the best price. Then in a second step, if two orders are at the same price, the order that is submitted the first represents a priority execution. The execution of these orders is done by the arrival of more aggressive orders which are usually market orders.

However, the limit order carries several risks. Three risks are related to limit orders: the risk of nonexecution, the risk of adverse selection, and the free trading option risk.

Rock (1991) ${ }^{2}$ was the first author treating of the hypothesis that informed investors place market orders to benefit from the information that they hold and whose concern is the immediate execution of their orders. Since Rock (1991), this hypothesis has been widely taken.

\footnotetext{
1 Minguet A., « la Microstructure des marchés d'actions, une approche empirique », Economica, 2003.

2 Rock K., « The specialists order book and price anomalies », Cahier de Recherche, Graduate School of Business-Harvard University, 1990.
} 
Optimal strategies of investors' choice between market orders, and limit orders are modelled by Parlour $(1998)^{3}$. This choice between the various types of orders depends also on the order book existing and the impact of orders on future investment strategies.

Parlour (1998) shows that the order flow is evolves systematically following the future arrival of orders and the existing order book, even in the absence of information asymmetry. For the author, the investor placing a limit order is subject to a risk of non-execution, however he/she is not looking for the immediacy of the exchange and this has no impact on his/her choice between placing a limit order and a market order. The choice between placing a limit order and a market order depends on transaction costs, the waiting costs and immediate execution costs. Investors seek to minimize the transaction costs and balance waiting costs and immediate execution costs.

An order driven market liquidity is conditioned by the existence of limit order traders whose behavior will have a direct impact on liquidity supply. Thus, limit orders in an order driven market determine its degree of liquidity and the process of fixation of the spread which represents the remuneration for liquidity suppliers. According to Biais, Foucault and Hillion $(1997)^{4}$, liquidity supply gain covers both: the service provided (immediacy), and the different risks faced by the limit orders placement. For Handa and Schwartz $(1996)^{5}$, this gain represents the main motivation of traders placing limit orders.

The use of a limit order depends on its probability of execution. Empirical work treating of the determinants of the probability of non-execution are not numerous. Hollifield, Miller Sandås and Slive (2004) ${ }^{6}$ modeled the probability of execution. A limit order execution is determined (inter alia) by the submission of market orders. Market orders may be at the origin of transaction against limit orders that are waiting in the order book, and therefore define the probability of limit orders execution.

Generally, in microstructure models, probability of execution and its determinants are related to the arbitration between a limit order and a market order. To explain this arbitration, several explanations may be advanced, including the exchange cost supported with this type of order, the type of information held by the investor and competition among liquidity providers.

The market order exchange cost affects directly the probability of execution of limit orders. Cohen et Al. $(1983)^{7}$ suggested the cost of Exchange as an explanation to the proportion of market orders.

When the market order traders are subjected to a significant costs, this impacts negatively on their willing to exchange with this type of orders. Therefore, the probability of execution of limit orders can be impacted negatively.

Foucault, Kadan and Kandel $(2005)^{8}$ treated of the interactions between the degree of investor's patience, investment strategies and the waiting time for the execution of a limit order.

The complete execution of a limit order means proportional waiting costs corresponding to the waiting time. This waiting time for total execution of a limit order is positively correlated to the orders arrival rate, and negatively to the size of the tick and the proportion of patient investors.

Being issued by patient investors, the turnaround time of limit orders is positively correlated to the proportion of patient investors. This contributes positively to the accentuation of the competition between investors placing limit orders, submitting more aggressive orders (the lowest price for sale and the highest in the purchase), in order to reduce the waiting time. This competition reduces the spreads, contributing positively to market liquidity.

For Foucault, Kadan and Kandel (2005), the competition level between limit orders traders is indicated by the spread. In the presence of a strong competition, to reduce the period of execution of their orders, limit orders traders offer more unfavorable prices which lowered the spread. The level of the spread is therefore negatively correlated with the degree of competition and the probability of execution.

\subsection{Liquidity supply and transaction costs}

Representing all the costs related to the use of the market to exchange securities, transaction costs result from the ownership transfer of financial assets.

On the one hand, the order processing from the moment of their receipt to their delivery involves charges, on the other hand, the desynchronization between the arrival of the request and the offering of the securities involves waiting costs for the execution and the research costs for the best counterparty.

\footnotetext{
3 Parlour C., « Price Dynamics in Limit Order Markets », Review of Financial Studies 11, 789-816, 1998.

${ }^{4}$ Biais B., Foucault T. et Hillion P., « Microstructure Des Marchés Financiers. Institutions, Modèles Et Tests Empiriques », Puf, 1997.

${ }^{5}$ Handa P., et Schwartz R.A., « Limit Order Trading », Journal Of Finance N ${ }^{\circ} 51,1835-1861,1996$.

${ }^{6}$ Hollifield B., Miller R., Sandas P., and Slive J., «Estimating the Gains from Trade in Limit-Order Markets », The Journal Of Finance, N ${ }^{\circ}$, 2006.

${ }^{7}$ Cohen K.J., Hawawini G.A., Maier S.F., Schwartz R.A., et Whitcomb D.K., «Friction in the trading process and the estimation of systematic risk », Journal of Financial Economics, 263-278, 1983

${ }^{8}$ Foucault T., Kadan O. et Kandel E., «The Limit Order Book as a Market for Liquidity », Review of Financial Studies, 1171-1217, 2001.
}

www.iosrjournals.org $35 \mid$ Page


In an order driven market, an investor looking for the best counterparty for his orders may use an electronic trading system or a broker to take advantage of his order book. The use of the market involves charges that the investor incorporates in the context of investment and trading decisions.

Several works were interested in the precise measure of transaction costs. They have dealt with the comparison of ex-ante measures (before transaction) and ex post measures (after transaction). This literature is interested in measures related to conducted transactions. While Perold approach $(1988)^{9}$ dealt with optimality of exchange decisions.

According to Perold (1988), the costs of implementation of decisions in financial assets portfolios investment determine the performance of the portfolio.

Transaction costs contains two types of costs. If one is explicit and easily identifiable and contained on the notices, the other is implicit. Explicit costs comprise the transaction costs and information costs and are fixed or proportional to the exchanged volume, in addition, they can be known in advance. Meanwhile, the implicit costs, represent the hidden part of the transaction cost. Gains and losses resulting from the negotiation process are strongly determined by the implicit transaction costs and define the profitability of the exchange.

Representing all of the costs previously known by the investor and appearing in the notices at the end of the transaction, the explicit part is a result of the market organization, of competition between intermediaries and taxation. It includes:

- Commissions,

- $\quad$ Brokerage fees,

- Taxation,

- $\quad$ Securities account management costs.

The implicit part of transaction costs is related to the execution conditions of the order. In contrast to the explicit costs, it is not easily identifiable. It is the part of the transaction costs that reflects the best market liquidity. It is composed of the spread and the market impact.

The spread represents the difference between the bid price and the ask price at a given time. On a quote driven market, it represents the spread of the market maker, while in an order driven market, it represents the limits of the market. It is an approximation of the cost of exchange immediacy service. It represents a market liquidity measure and in what follows will be the subject of further explanation

The market impact is the effect that a market participant has when he/she buys or sells an asset. It represents the displacement of the price equilibrium due to the importance of the trading or the arrival of new information. It is a commonly known as additional cost called execution cost. It represents a price concession in case of sale, and a price concession obtained in case of purchase.

In terms of degree of importance, market impact represents the most important component of transaction costs and their inevitable element. In second place come the costs associated to a service of liquidity obtained by the use of an intermediary. Detention charges and taxation is the least important costs. On the other hand, the best measure to approximate the liquidity of market remains the spread.

\subsubsection{Transaction costs impact}

The impact of transaction costs has been the subject of a multitude of studies. For Benston and Smith (1976), transaction costs negatively affect portfolios building and their diversification. They decrease securities demand and channel investment to the non-risky investments.

For Schwartz (1993), the transaction costs impact on the investors' behavior is negative. They are negatively correlated with expected yields to investors. In addition, they prevent frequent portfolios review, and push investors to judge their placement appropriateness.

Transaction costs increase securities acquisition costs and reduce capital gains in case of sale. They involve a decrease in liquidity via the decline in the level of the exchange. Transaction costs negatively influence the investor behavior by increasing his/her impatience fearing a significant variation of the price during its waiting time.

Transaction costs can negatively impact market liquidity. On the one hand, the decline in the number of market participants would imply a slimming of the orders flow, on the other hand it involves the remoteness of transaction prices of the actual values of the traded securities. The combination of these two factors negatively affects market liquidity.

\subsubsection{The spread: main market liquidity measurement tool:}

The spread represents the difference between the price at which an asset is purchased and the price at which this same asset is sold at the same time. It is a measure of the liquidity available at any given time. It represents the remuneration of the intermediary and compensates liquidity suppliers.

${ }^{9}$ Perold A.F., « The implementation shortfall: paper vs. Reality », Journal of Portfolio Management, 14, 4-9. 1988. 
In a quote driven market, several market makers are competing for each asset. Market makers set a bid price and an ask price for each asset. The bid price is the price at which the market maker is immediately ready to buy. And the ask price is the price at which he is immediately ready for sale. In a quote driven market, the spread corresponds to the difference between the best ask price and the best bid price offered by the market maker.

Competition also exists in an order driven market between traders. The spread in an order driven market corresponds to the difference between the best limits of the order book.

For Demsetz (1996), in an order driven market, there are two equilibrium prices: the best high limit allowing certain investors an immediacy in the acquisition of securities, and the best low limit allowing an immediacy of transfer of securities.

The transaction price will be the one of the best upper limit (ask) if the transaction is done at the initiative of a buyer, and will be the best limited inferior (bid) if the transaction is done at the initiative of a seller.

In addition, certain transactions can be negotiated (not at the bid price or the ask price) at a price located within this spread, or even outside, therefore generally, the quoted spread does not reflect the transaction cost.

\subsection{The profitability of liquidity offer in an order driven market}

In an order driven market, is it more profitable to be a liquidity supplier by placing limit orders or to be a liquidity demander by placing market orders?

This question of the profitability of liquidity offer refers to the gain or loss of performance used by investors and resulting from the negotiation process. This profitability is a function of the objective of the exchange, risks and costs of the exchange as well as the compensation received for agreeing to support these risks.

Harris and Hasbrouk (1996) ${ }^{10}$ treat of the profitability of liquidity offer. They measure the transaction costs for different choices of orders ${ }^{11}$. They are interested in two types of orders: the limit orders expiring around market closing, if they are not executed, and market orders.

They compare the execution price of the order to a reference price for the transaction, in order to estimate the performance of the limit orders expiring around market closing if they are not executed, and those immediately accepting the market price.

They consider an ex ante measure (according to the transaction costs literature) for which the reference price is the one that allows an immediate exchange (the market price) at the time when the order is placed. And they consider an ex post measure which takes as its reference the market prices observed five minutes after the execution of the order. They also take into consideration the opportunity cost of a non-executed or partially executed order.

By comparing the conditions of execution of a limit order with a market order, the gain or the loss of a limit order performance can be highlighted.

The authors differentiate orders depending on their size and the difference between the price offered by the specialist for an immediate sale or a purchase. They analyze the performance of a limit pricing strategy as it represents for the counter party a more or less attractive offer compared to the price proposed by the specialist. The ex-ante measures show a negative correlation between the performance of a limit order and the size of the order.

The trader's behavior determines liquidity supply. For the uninformed investors, traders should offer an attractive limit price. This would increase the execution probability and would allow the protection of the client against the non-execution risk. However, this negotiators strategy increases also the risk of loss against informed investors. Negotiators should be patient and do not depend on the exchange.

The existence of discretionary investors able to agree on a deadline to negotiate their exchange and operators able to waive any transaction, if their limit order is not executed, is a sine qua none condition to the existence of liquidity offer.

Order driven market liquidity is based on the combination of several complementary elements. It requires: the presence of buyers and sellers, investors motivated by information and other investors driven by liquidity, patient negotiators who are liquidity providers, and others favoring the acceptance of these trading conditions.

\footnotetext{
${ }^{10}$ Harris L., et Hasbrouck J., « Market vs. Limit Orders: The SuperDOT Evidence on Order Submission Strategy », Journal of Financial and Quantitative Analysis 31, 213-231, 1996.

${ }^{11}$ For a sample of 144 listed firm on the NYSE (randomly selected), they analyze the order flow in the automated system SuperDot143 between november 1990 et January 1991 and constitute the database TORQ (Trades, Orders, Revisions and Quotes).
} 
For Glosten (1994), if the number of patient negotiators is low, other negotiators are encouraged to provide liquidity, via announcing limit prices. In the presence of a sufficient number of liquidity suppliers in an order driven market, the liquidity supply is possible even in the presence of information asymmetry.

In an order driven market, there must be an incentive to offer liquidity to uninformed negotiators, and the expected gain should offset expected losses against better informed operators. In addition to the risk of information asymmetry, other risks characterize the limit orders.

\section{Limit Order Submission Risks}

Investors placing limit orders face several risks. The limit order can be executed or not. In addition, it can be executed against an informed investor that "captures" all limit orders to purchase (sale) that the prices are lower (higher) than their own estimate of the values of the assets in question.

In addition to the risks of non-execution and adverse selection, in a situation of information asymmetry, the investor placing a limit order runs a free trading option risk.

Furthermore, if the asset value varies, this makes the price associated with the limit order lapsed, and causes the same loss for the limit order trader, referred to as « the winner's curse ».

Thus, the limit order carries several risks. Three risks are related to orders limit: the risk of nonexecution, the risk of adverse selection, and the free trading option risk.

\subsection{The risk of non execution}

A limit order is characterized by a size and by a (minimum) maximum price at which the underwriter of the order is ready to buy (sell) assets. The priority in terms of time and price is the main rule of accumulation of limit orders in the order book.

Several parameters determine the partial or complete limit orders execution. Firstly, the fixed limit prices in the order book condition part execution or full of limit orders. The validity period of orders and the arrival of orders to the market in the opposite direction could prevent complete execution of limit orders.

Handa and Schwartz (1996) ${ }^{12}$ deal with limit orders and are particularly interested in assessing their risk of non-execution. They show that the non-execution costs of limit orders are not always significant. In the case of an execution, the non-execution cost measures the loss of opportunities associated to it.

Handa, Schwart and Tiwari (1998) ${ }^{13}$ deal with a sequential model bi-periodique. They include the risk of non-execution and the risk of adverse selection. The risk of non-execution depends on the distribution of the investors in the opinion on the assets value.

Foucault (1999) ${ }^{14}$ considers a trading day decomposed into infinite discrete time intervals, the framework in which he is placed is therefore wider. He leads to the same conclusion as his predecessors. The assets value is subject to variations, hence, each limit order underwriter is subject to the winner's curse. In his model, no information asymmetry is introduced. The distribution between the types of orders (limit orders and market orders) depends on the asset price volatility. The asset price volatility has an impact on the risk of adverse selection.

The assets volatility positively influences the proportion of limit orders. There is a positive correlation between asset volatility and the limit orders proportion. However, because of the importance of limit orders, the risk of non-execution remains important. The more price volatility is important, the more the spread is large. The risk of non-execution also increases limit orders prices. In the presence of a significant risk of nonexecution of a limit order, the investor will prefer placing a market order that will guarantee immediate execution in return for an immediacy cost.

\subsection{Free trading option risk}

The limit order trader runs a risk of non-execution, a risk of adverse selection, and a free trading option risk. Many are the differences between a limit order and a market order, which include free trading option.

The investor who wants to sell (buy) a share at a limit price gives an option to buy (of sale) of this share whose lifetime is confused to the validity duration of the order. Once the order is placed, the limit order seller (buyer) depends on the decision of the buyer (seller).

According to his degree of impatience, an investor who is willing to sell (buy) a share faces a choice to make. He/she decides either to make the sale (purchase) immediately if he/she accepts to receive the price corresponding to the better lower limit (higher) of the order book, or to place a sell order (buy order) above

\footnotetext{
${ }^{12}$ Handa P., et Schwartz R.A., « Limit Order Trading », The Journal Of Finance, 51, 1835-1861, 1996.

${ }^{13}$ Handa P., Schwartz R.A., et Tiwari A., «Determinants of the bid-ask spread in an order driven market », Working paper, University of Iowa, 1998.

${ }^{14}$ Foucault T., « Order Flow Composition And Trading Costs In A Dynamic Limit Order Market », Journal Of Financial Markets, 193-226, 1999.
} 
(below) the lower limit (upper limit). The gap between the best lower limit of the order book and the maximum price expressed by the seller of the asset will determine the order execution period.

In contrast to the market order trader who is considered as a « urgent » investor, the limit order trader is patient. The latter sets an upper selling limit and a lower buying limit to what he considers to be the equilibrium price.

For Handa and Schwartz (1993) ${ }^{15}$, if prices follow a random walk, and as long as the market order trader escapes to the two risks that limit order traders run, all investors will want to place their orders at the market price and the market equilibrium could not be achieved.

The existence of limit orders is necessary to order driven market equilibrium. This has been highlighted by Handa and Schwartz (1993) on the NYSE, and Hamon Handa Jacquillat and Schwartz (1993) on the ACC system.

The choice of the order type to place expresses the degree of the investors' impatience. Thus, there are patient investors and urgent investors (Glosten (1994)). The latters shock prices and cause a temporary imbalance and diverge the price from their fundamental values. They are liquidity seekers who are willing to pay for their impatience, and at the same time pay the market for liquidity-providing service.

Limit orders provide benefit opportunities to other investors. That can be explained by the chronology of the placement of limit orders and market orders. A limit order offers a free option, so the underwriter of a sell limit order (buy limit order) offers an option to purchase (sale) on this asset.

For Biais, Glosten and Spatt (2005) ${ }^{16}$, an investor acting as a counterparty for a limit order and reacting more quickly than a limit order trader may exercise a free trading option before the limit order would be cancelled or modified.

\subsection{Risk of anti-selection}

The limit order trader runs several risks, including the risk of information asymmetry (adverse selection). The bagging cost measures the loss associated with the revelation of private information to the entry of the order book.

As a result of the information asymmetry between the various orders traders, the risk of anti-selection is the risk for a limit order to be paired with a market order placed by an informed investor, and thus affecting the value of the asset.

For a seller using a limit order, the risk of anti-selection occurs when a favorable information to the issuer of the share is unknown at the moment where he places his order. The possessor of the information captures all orders that the price is between the old and the new equilibrium price.

This negatively affects the limit order trader interests. This could be explained by the fact that the limit (for sale) which was higher than the old equilibrium price is actually less than the new price.

Glosten $(1994)^{17}$ was the first author to assess the risk of anti-selection for an order driven market. Subsequently the literature who has dealt with the anti-selection cost in an order driven market have proliferated. Glosten (1994) carries out the construction of order book. He studied the interactions between limit order traders and market order traders.

Investors placing limit orders make a calculation comparing the gain to the costs of limit orders (because of all the risks they run). At equilibrium, the proposed securities quantity determines the price fixed by the limit order.

In another register, Harris and Hasbrouk (1996) through the comparison of different types of order aim to assess the risk of anti-selection of limit orders. The authors are interested in the assessment of the performance of the market orders and the limit order on a sample of securities listed on the NYSE. They compare the price of execution of a best limit order on the same side of the order book after the execution via the use of an ex-post performance measure. The authors interpret it as an approximation of the cost of the antiselection. They conclude that limit orders are more exposed to the risk of anti-selection than market orders.

Biais, Martimort and Rochet (2000) are placed in their model in a situation of information asymmetry in the presence of a single informed risk-averse investor. Risk neutral investors compete for liquidity supply.

Price grid which is proposed by liquidity providers is non-linear. Liquidity providers set different prices for their anticipation of the asset value and at the same time and are positively correlated with the order size. In this case, the equilibrium for which they get a profit is unique. However this advantage becomes void in the case of an infinite number of investors.

Handa and Schwartz (1996), are interested in limit order profitability analysis in order to treat of the choice to make between the placement of a limit order and a market order. The gains made by a limit order

\footnotetext{
${ }^{15}$ Handa, P., Et R.A. Schwartz, « limit order trading », Working paper, New York University, 1993.

${ }^{16}$ Biais B., Glosten L. et Spatt C., « Market Microstructure: A Survey of Microfoundations, Empirical Results, and Policy Implications », Journal of Financial Markets, Vol. 8, No. 2, pages 217-64.

${ }^{17}$ Glosten L.R., «Is The Electronic Open Limit Order Book Inevitable » Journal Of Finance N4, 1994.
} 
trader face to liquidity-driven agent will outweigh its potential losses facing an informed investor (the same conclusion as that Glosten (1994) reached).

The price variations following transactions with an information driven investor are permanent because prices adjust to new information. However, price variations associated with a transaction with a non-informed investor are temporary.

Handa, Schwartz and tawari (1998), by introducing the information asymmetry, deal with the antiselection risk. The equilibrium bid and ask prices depend on the anti-selection risk. The heterogeneity of opinions on the assets value combined with the information asymmetry determines the spread. Even in the absence of information asymmetry and because of the competition between investors who are valuing differently the assets, the spread is non-zero (positive spread).

\section{Conclusion}

In an order driven market, investors have the opportunity to place buy and sell orders and be liquidity supplier, or to be seeking for liquidity in order to be executed immediately against offerings from other investors. According to their needs and motivations, investors can place different types of orders. Thus, the supply of liquidity in order driven markets is provided by limit orders traders.

Many are the risks that limit order traders run, liquidity demanders avoid these risks by submitting market orders that the execution is immediate. In return, they agree to pay the spread that liquidity providers impose. In addition, there may be a price risk, also called market impact, if the quantity demanded is greater than the quantity available.

The choice between supply and demand of liquidity is function of volatility, the size of the spread and the time remaining before the end of the negotiation.

Diversity is a sine qua none condition to market liquidity. On the one hand, the presence of negotiators capable of neglecting the risk of non-execution, and patients is necessary to the supply of liquidity in an order driven market. On the other hand, protection against the risk of adverse selection is necessary to these negotiators.

The market viability is based, inter alia, on the presence of liquidity providers. In order driven markets, this function is performed primarily by institutional investors and brokers.

\section{References}

\section{Journal Papers:}

[1] Glosten L.R., « Is the Electronic Open Limit Order Book Inevitable » Journal of Finance N4, 1994

[2] Rock K., «The specialists order book and price anomalies », Cahier de Recherche, Graduate School of Business-Harvard University, 1990.

[3] Parlour C., « Price Dynamics in Limit Order Markets », Review of Financial Studies 11, 789-816, 1998.

[4] Handa P., et Schwartz R.A., « Limit Order Trading », Journal Of Finance N51, 1835-1861, 1996.

[5] Hollifield B., Miller R., Sandas P., and Slive J., «Estimating the Gains from Trade in Limit-Order Markets », The Journal Of Finance, $\mathrm{N}^{\circ} 6,2006$.

[6] Cohen K.J., Hawawini G.A., Maier S.F., Schwartz R.A., et Whitcomb D.K., « Friction in the trading process and the estimation of systematic risk », Journal of Financial Economics, 263-278, 1983

[7] Foucault T., Kadan O. et Kandel E., « The Limit Order Book as a Market for Liquidity », Review of Financial Studies, 1171-1217, 2001.

[8] Perold A.F., « The implementation shortfall: paper vs. Reality », Journal of Portfolio Management, 14, 4-9. 1988.

[9] Benston, G.J. and Smith, Jr., C.W., « A transaction cost approach to the theory of financial intermediation», Journal of Finance, 31, $215-231$.

[10] Schwartz R., « Competition and efficiency», in Kenneth Lehn and Robert Kamphuis, eds., Modernizing U.S. Securities Regulation: Economic and Legal Perspectives. Homewood, IL: Business One-Irwin, 1993.

[11] Harris L., et Hasbrouck J., « Market vs. Limit Orders: The SuperDOT Evidence on Order Submission Strategy », Journal of Financial and Quantitative Analysis 31, 213-231, 1996.

[12] Handa P., Schwartz R.A., et Tiwari A., « Determinants of the bid-ask spread in an order driven market », Working paper, University of Iowa, 1998.

[13] Foucault T., « Order Flow Composition and Trading Costs In A Dynamic Limit Order Market », Journal Of Financial Markets, 193226, 1999

[14] Biais B., Glosten L. et Spatt C., «Market Microstructure: A Survey of Microfoundations, Empirical Results, and Policy Implications », Journal of Financial Markets, Vol. 8, No. 2, pages 217-64.

\section{Books:}

[15] Minguet A., « la Microstructure des marchés d'actions, une approche empirique », Economica, 2003.

[16] Biais B., Foucault T. et Hillion P., « Microstructure Des Marchés Financiers. Institutions, Modèles et Tests Empiriques », Puf, 1997. 